\title{
"É dando que se recebe": as políticas de benefícios de uma fábrica de calçados no Ceará
}

\author{
Izabel Cristina Ferreira Borsoi ${ }^{\mathrm{I}, 1}$ e Raquel Maria Rigotto ${ }^{\mathrm{II}, 2}$ \\ ${ }^{\mathrm{I}}$ Departamento de Ciências Sociais da Universidade Federal do Espírito Santo \\ ${ }^{\text {II }}$ Departamento de Saúde Comunitária da Faculdade de Medicina \\ da Universidade Federal do Ceará
}

\begin{abstract}
Como parte do intenso reordenamento do mundo produtivo, o Nordeste brasileiro tem atraído fábricas do Sul e do Sudeste, principalmente devido às vantagens oferecidas pelos governos e à mão-de-obra barata. Este texto visa discutir aspectos relacionados à situação de trabalho e à política de benefícios de uma fábrica de calçados instalada no Ceará. A discussão fundamenta-se em observações e entrevistas com gerentes e trabalhadores. A análise indica que esse conjunto de práticas não impacta de modo efetivo sobre rendimento e o bem-estar dos trabalhadores. $\mathrm{Na}$ realidade, constitui-se num esforço para torná-los mais atrelados à empresa, levando-os a sentirem-se em dívida com seus empregadores.
\end{abstract}

Palavras-chave: Fábricas, Calçados, Trabalhadores, Benefícios.

"For it is in giving that we receive": the benefit policies of a shoe factory in Ceará State

As a part of the productive world rearrangement, the Northeast of Brazil has attracted many industrial enterprises from South and Southeast, due mainly to the advantages offered by governments and the inexpensive work force. This article intends to discuss some features of the working conditions and of the benefit policies in a shoe factory settled in Ceará State. The discussion is based on observations and interviews with managers and workers. The analysis indicates that this set of practices doesn't bring effective impacts on workers' income and welfare. In fact, it consists of an effort to make them more linked to the enterprise, leading them to feel in debt to the employers.

Keywords: Factories, Shoes, Workers, Benefits.

\section{Introdução}

\begin{abstract}
A década de 1970 inaugura um novo momento do capitalismo, quando, em meio à crise do modelo fordista de acumulação e organização da produção, inicia-se um intenso processo de reestruturação centrado, entre outros aspectos, na re-localização de empreendimentos produtivos, na incorporação de novas tecnologias ou modelos de organização do trabalho e na diversificação das formas de contratação dos trabalhadores, apontando para a flexibilização e para a precarização de diferentes dimensões do mundo produtivo.
\end{abstract}

Para Harvey (2002), o novo modelo de acumulação apóia-se

na flexibilidade dos processos de trabalho, dos mercados de trabalho, dos produtos e padrões de consumo. Caracteriza-se pelo surgimento de setores de produção

\footnotetext{
1 Psicóloga, mestre em psicologia social, doutora em sociologia e professora do Departamento de Ciências Sociais da Universidade Federal do Espírito Santo.

2 Médica do trabalho, doutora em sociologia, professora do Departamento de Saúde Comunitária da Faculdade de Medicina da Universidade Federal do Ceará. Coordenadora do Núcleo Tramas (Trabalho, Meio Ambiente e Saúde para a Sustentabilidade) e coordenadora da pesquisa na qual se fundamenta este trabalho.
} 
inteiramente novos, novas maneiras de fornecimento de serviços financeiros, novos mercados e, sobretudo, taxas altamente intensificadas de inovação comercial, tecnológica e organizacional. A acumulação flexível envolve rápidas mudanças dos padrões do desenvolvimento desigual, tanto entre setores como entre regiões geográficas, criando, por exemplo, um vasto movimento no emprego no chamado "setor de serviços", bem como conjuntos industriais completamente novos em regiões até então subdesenvolvidas (tais como a "Terceira Itália", Flandres, os vários vales e gargantas do silício, para não falar da vasta profusão de atividades dos países recém-industrializados) (p. 140).

Dentre os vários aspectos do novo modelo de acumulação apresentados por Harvey, convém destacar a migração de fábricas localizadas em regiões densamente industrializadas para territórios sem experiência fabril. Essa transferência tem-se dado em razão da necessidade de expansão do capital e vem sendo motivada pelas vantagens encontradas nos novos territórios, tais como o barateamento dos custos de instalação e de mão-de-obra. De forma diversa do que ocorre em seus lugares de origem, onde encontram dificuldades para impor aos trabalhadores um modo rígido de organização do trabalho, essas empresas buscam, então, um trabalhador facilmente "adestrável" e que se submeta às rigorosas exigências da produção. Humphrey (1995) afirma que essa rigidez tem sido comum em fábricas localizadas principalmente em regiões rurais, onde as taxas de desemprego são elevadas pela carência de alternativas de trabalho.

Alguns estados do Nordeste brasileiro têm sido alvo dessa mobilidade do capital. Entre eles está o Ceará, que vem abrigando empresas oriundas das regiões Sul e Sudeste, em particular a partir do final da década de 1980. Em geral, são fábricas baseadas em trabalho intensivo e cujas atividades prescindem de força de trabalho qualificada. Incentivadas pelo programa de atração de investimentos industriais do governo estadual - eixo de seu Plano de Desenvolvimento Sustentável -, ao instalarem-se, elas encontram um conjunto de vantagens, tais como atraentes incentivos fiscais, concessões de terrenos e de infra-estrutura por parte das prefeituras, além de mão-de-obra barata e abundante (Borsoi, 2005; Rigotto, 2007).

Dessa forma, vários municípios do interior do Ceará, alguns deles próximos à capital, estão experimentando uma espécie de surto de industrialização, sofrendo, por isso, um intenso redimensionamento de suas estruturas populacional e urbana, de sua paisagem e de sua cultura local, em um verdadeiro processo de des/re-territorialização (Haesbaer, 1997; Rigotto, 2004). Ressaltem-se, ainda, as significativas degradação e contaminação ambientais e a baixa qualidade dos postos de trabalho oferecidos, que, muitas vezes, podem ser qualificados como perigosos, insalubres ou penosos.

São fábricas de calçados, tecidos, confecções, alimentos, bebidas, embalagens etc. que encontram nesses novos territórios os benefícios que deixaram de usufruir em suas matrizes. Dentre esses ramos de produção, destaca-se a indústria calçadista, uma das que mais tem crescido. As unidades subsidiadas que se instalam em solo cearense são de empresas originárias do Sul e do Sudeste, mais especificamente do Rio Grande do Sul e de São Paulo. Em grande parte das vezes, as matrizes permanecem em seus lugares de origem, onde mantêm as atividades mais relacionadas à manutenção do centro de poder do empreendimento design, marketing, administração de pessoal etc. Outras vezes, as fábricas migram de forma integral, fechando as antigas unidades.

Populações historicamente vivendo situações de penúria social são vistas como mãode-obra abundante e barata. Sua falta de experiência industrial anterior e sua precária organização sindical conformam, do ponto de vista dos empresários, contextos favoráveis ao rigor na escolha dos trabalhadores a serem contratados e a "moldar o trabalhador como a empresa quer" (Rigotto, 2004). Na maioria das vezes contratam pessoas jovens entre 18 e 30 anos, preferencialmente mulheres, dada a construção simbólica de que elas estariam mais 
aptas para trabalhos que exigem paciência, atenção e capricho, como costura, bordado, acabamento, embalagem etc.

Sendo quase sempre a referência de emprego do lugar, essas empresas podem exigir o máximo dos trabalhadores, pouco dispondo-se a oferecer, a começar pela faixa salarial, que, em geral, fica em torno do salário mínimo. De acordo com estudo do Instituto de Pesquisa Econômica Aplicada (IPEA), a indústria coureiro-calçadista no Ceará chega a oferecer remuneração média mensal inferior em até $40 \%$ àquela que oferece no Sul e no Sudeste do País (Noronha \& Turchi, 2002). Além da remuneração, essas empresas oferecem aos trabalhadores o que denominam de política de benefícios, a qual, entretanto, nem sempre consiste no que poderíamos relacionar a garantias de trabalho ou a algo que traga algum ganho efetivo para o trabalhador.

O objetivo deste artigo é discutir alguns aspectos da situação de trabalho e, principalmente, dos programas de benefícios de uma fábrica de calçados femininos instalada no Ceará. Como se verá, procuramos mostrar que, além de não impactar de modo efetivo sobre os rendimentos e o bem-estar dos trabalhadores, tais políticas acabam atuando como meio de atrelamento destes à empresa, fazendo com que se sintam em dívida com seus empregadores.

O tema discutido aqui é um desdobramento da pesquisa "Violência e trabalho: acidentes de trabalho e humilhação na indústria calçadista do Ceará", ${ }^{3}$ cujo objetivo foi descrever e analisar as formas de violência manifestadas nos acidentes de trabalho e em situações de humilhação em três unidades fabris de duas empresas calçadistas de grande porte, oriundas da região Sul e instaladas no Ceará a partir de 1995.

A pesquisa consistiu no estudo do processo de trabalho em cada uma dessas unidades - situadas na Região Metropolitana de Fortaleza, ao norte e ao sul do Estado -, tendo-se realizado por meio de entrevistas com informantes-chave (dentre eles, ocupantes de cargos de direção e da área de recursos humanos) e observação direta; descrição e análise do perfil dos acidentes de trabalho com trabalhadores dessas indústrias oficialmente registrados no período de 2000 a 2005, a partir de dados da Previdência Social; caracterização aprofundada de diversos aspectos dos acidentes registrados em 2006, tomando como referência dados das Comunicações de Acidentes de Trabalho (CATs); e informações obtidas mediante entrevistas estruturadas, envolvendo, ao todo, 134 trabalhadores vítimas de acidentes nessas fábricas. $\mathrm{O}$ fenômeno da humilhação foi abordado por meio de entrevistas semi-estruturadas com 20 trabalhadores e trabalhadoras das três unidades referidas e que tinham vivenciado situações de constrangimento em seus locais de trabalho.

A discussão apresentada especificamente neste artigo baseia-se em observações e em informações colhidas entre trabalhadores e ocupantes de cargos de direção e de recursos humanos de uma dessas unidades.

\section{A fábrica e os benefícios: uma dívida que só se paga com trabalho}

A fábrica em questão, que aqui designaremos de Sigma, integra um conjunto de quatro unidades de uma mesma empresa no Ceará, cuja matriz está localizada na região Sul do Brasil. Seu quadro funcional é formado por cerca de 2.340 trabalhadores, havendo uma predominância de mulheres (em torno de 1.500), bem como de jovens com menos de 30 anos. A forte presença feminina costuma ser associada ao fato de que a produção de calçados

3 Pesquisa realizada com financiamento do CNPq e concluída em novembro de 2007, conforme relatório elaborado por Raquel Maria Rigotto, Regina Heloisa Maciel, Izabel Cristina Ferreira Borsoi e outros colaboradores. 
envolve um grande conjunto de operações leves e delicadas, como costura e bordado. Entretanto, podemos deduzir que, em parte, isso se dá por serem as mulheres consideradas também mais dóceis, menos questionadoras e, por isso, mais facilmente controláveis. Essa postura encontra-se em acordo com o crescimento da feminização do trabalho, que tem ocorrido em todas as esferas do mundo laboral, seja na produção, seja no setor de serviços, como mostram Antunes (1995, 2000) e Hirata (2002).

Além desses trabalhadores, cujos contratos são regidos pela Consolidação das Leis do Trabalho (CLT), a fábrica mantém, ainda, vínculo indireto com outros grupos de trabalhadores, que, mediados pelos chamados ateliês ${ }^{4}$, são responsáveis por realizar tarefas que envolvem costura manual e confecção de determinados componentes que servem de adorno para os sapatos. Esses trabalhadores costumam atuar em suas próprias casas, recebendo por peça produzida e, às vezes, envolvendo também filhos menores, como mostra Rigotto (2004, 2007).

A produção média diária da Sigma chega a 15 mil pares de calçados. São 10 linhas de produção distribuídas em dois grandes galpões que funcionam em dois turnos, conjugando as atividades da esteira fordista e do sistema de células ou grupos. ${ }^{5}$ Essas atividades incluem corte das peças que compõem o calçado, colagem, costura, montagem, acabamento e embalagem. A maioria dos trabalhadores realiza suas atividades em pé, sob ruído e calor intensos.

Ao contrário do que se poderia pensar, as células introduzidas na produção, há menos de um ano, não significaram redução da carga de trabalho nem maior domínio dos trabalhadores sobre o processo de trabalho ou sua autonomia. Além disso, há a exigência de uma polivalência que, na verdade, restringe-se à habilidade para realizar duas ou três operações simplificadas, muitas vezes com vistas a possibilitar a substituição de colegas faltosos, e não para enriquecer o conteúdo das fragmentadas tarefas exercidas. O controle externo sobre o trabalho tornou-se ainda mais intenso - as metas de produção são estabelecidas para o grupo, fazendo com que cada trabalhador interiorize parte das incumbências da hierarquia e fique atento ao desempenho dos colegas. $O$ cronômetro continuou sendo o grande parâmetro de avaliação de velocidade e destreza na realização das tarefas. Para alguns trabalhadores, o resultado disso tudo tem sido o aumento do ritmo de produção e o maior volume de trabalho, pois esse sistema permite reduzir o número de pessoas na linha produtiva sem que necessariamente as metas sejam revistas levando-se em conta a nova dimensão dos grupos.

Em épocas de maior demanda, é comum trabalharem em horas extraordinárias, as quais já não são computadas e pagas como horas extras, devido ao sistema de "banco de horas", que permite flexibilizar a jornada e desonerar o empregador pelo trabalho excedente. Isso significa que cada hora a mais trabalhada dará direito a uma hora de folga extra a ser compensada anualmente. Essa prática tem sido permitida por força de uma medida adotada pelo governo federal, em meados da década de 1990, para implementar maior flexibilização das relações de trabalho. Para Krein (2001), o

banco de horas, aspecto de grande conflitividade das negociações coletivas nos anos 90, introduz a possibilidade de compensação da jornada, que passa a ser não mais semanal e sim anual. A empresa pode organizar a utilização do tempo de trabalho conforme os seus ciclos de produção durante o ano (p. 3).

\footnotetext{
4 Trata-se de pequenas empresas contratadas pela fábrica para realizar determinadas etapas da confecção do produto fora de sua linha de produção, especialmente aquelas que exigem trabalho manual.

5 Grupos de trabalhadores treinados para serem polivalentes, de modo que possam se revezar em tarefas distintas na linha de produção. No caso da fábrica de calçados em questão, uma célula costuma ser composta por um supervisor, um revisor, um auxiliar e os demais trabalhadores que executam as operações de confecção do calçado.
} 
O funcionamento do banco de horas de uma forma regular tem, por si só, impacto negativo na vida do trabalhador, uma vez que, além de não remunerar as horas extras, ainda o constrange "a estar mais disponível para a empresa, sem poder planejar seu período de férias ou seu final de semana de acordo com a própria conveniência" (Rigotto, 2004, p. 26). No caso da Sigma, parece haver ainda uma agravante. Há informações que indicam que esse tempo de trabalho suplementar dificilmente é pago de forma integral, sequer por meio de folgas. Isso significa, em parte, produção gratuita para o empregador, com prejuízo apenas para o trabalhador, que despendeu mais esforço sem qualquer retorno, seja financeiro, seja como repouso. ${ }^{6}$

Frente às cobranças por trabalho em jornada suplementar, não há como os trabalhadores recusarem-nas, pois fazem parte da conduta da empresa a advertência e a ameaça de demissão para os que se negam a obedecer a convocação para o banco de horas. Para Borsoi (2005, p. 94), em situações como essas, emerge entre os trabalhadores "a consciência aguda da própria descartabilidade, há a noção clara de que cada um é qualquer um, que suas diferenças individuais são igualadas quando se trata de comprar ou descartar sua força de trabalho".

O medo da perda do emprego, aqui, é um aspecto crucial: freqüentemente, as alternativas de trabalho e de geração de renda mais compatíveis com a tradição histórica do lugar (no caso, o artesanato de cerâmica, o bordado, a agricultura camponesa) são pouco apoiadas pelas políticas públicas. Assim, fábricas como a Sigma costumam ser, na localidade, as únicas ou, no mínimo, a maior referência de emprego, não tanto pela política salarial praticada (que, na linha de produção, costuma ter como base o salário mínimo, conforme já afirmamos), mas por significar, muitas vezes, um reduto de garantias trabalhistas mínimas leia-se: trabalho formal com direito a carteira profissional assinada, salário em dia, folgas e licença-saúde remuneradas. Afora isso, oferecem o que chamam de "quadro de benefícios", que, em parte dos casos, integram também as ações previstas nos programas de responsabilidade social, os quais estabelecem fundamentalmente determinados compromissos da empresa para com a coletividade ou com o município no qual se instalam, a própria empresa assumindo, em tese, uma parcela das incumbências que antes cabiam ao Estado.

Movidas pela necessidade de manterem-se competitivas e conquistarem certificação internacional da qualidade de suas práticas organizacionais, essas empresas precisam apresentar projetos que prevêem ações sociais e ambientais internas e externas (Ximenes, 2004). Por causa disso, acabam, de um modo ou de outro, envolvendo os trabalhadores em seus programas: primeiro, mediante ações internas, propõem-se a atender à necessidade de manter o que consideram qualidade de vida no trabalho e, segundo, procuram beneficiar instituições ou grupos da localidade onde atuam, como escolas, igrejas, associações comunitárias e filantrópicas, movimentos ecológicos etc.

No que diz respeito aos benefícios sociais, cabe esclarecer que não se referem, necessariamente, a direitos sociais. Enquanto estes últimos "correspondem, formalmente, a prerrogativas, reconhecidas pelo Estado capitalista às classes trabalhadoras, que implicam uma melhoria das condições de trabalho e de vida dessas classes, bem como do nível de consumo das massas" (Saes, 2006), os benefícios sociais são considerados "facilidades, conveniências, vantagens e serviços que as organizações oferecem aos seus empregados" (Chiavenato, 1983, p. 77), ${ }^{7}$ não constituindo, portanto, algo cuja concessão seja obrigatória. É importante salientar, entretanto, que a expectativa em torno dos benefícios sociais que

6 Cabe lembrar que, de acordo com a CLT, no seu artigo 59, a remuneração da hora suplementar deve, obrigatoriamente, ser pelo menos $20 \%$ maior do que a da hora normal ou, então, ser compensada pela correspondente diminuição de horas de trabalho em outro dia, de forma a não ultrapassar o horário normal da semana ou a não exceder o limite máximo de 10 horas diárias (Costa \& Ferrari, 1990).

7 Ainda segundo o autor, tais benefícios "estão intimamente relacionados com a gradativa conscientização da responsabilidade social da organização". 
empresas ou instituições possam oferecer é de que eles tenham algum impacto efetivo na remuneração final de seus trabalhadores, funcionando, nesse caso, como uma espécie de "salário indireto".

No caso da Sigma, de acordo com sua gerência, a política de benefícios é extensa e inclui ações diretamente voltadas para empregados e seus familiares, como serviços de ginecologia e de fonoaudiologia, ginástica laboral, massagem relaxante nas dependências da fábrica, kits escolares para filhos de funcionários, convênio com farmácia, homenagem aos aniversariantes, culto semanal antes da jornada matutina, teatro e coral dos funcionários.

Vale ressaltar que tem implicações significativas um serviço de atendimento ginecológico oferecido por uma empresa na qual $66 \%$ de seus empregados são do sexo feminino. Do lado da empresa, pode constituir-se como importante estratégia para evitar ausências ao trabalho, que seriam justificadas pela necessidade de consultas ou de realização de exames preventivos preconizados pela saúde pública. Do lado das trabalhadoras, isso implica dificuldades para justificarem a procura de um outro profissional da mesma especialidade fora de seu ambiente laboral, alguém com quem possam construir um vínculo médico-paciente que não passe pela relação enviesada com a própria empresa. Em síntese, não há como negar que interessam à fábrica o controle da natalidade, a redução de afastamentos por possíveis desconfortos menstruais e o acompanhamento de trabalhadoras gestantes para que continuem produzindo sob condições inadequadas e em posições desconfortáveis, sem que a empresa precise assumir o ônus de uma ou outra licença médica.

Da mesma forma, o serviço de fonoaudiologia viabiliza a realização dos exames complementares exigidos pela legislação trabalhista no caso de exposição a ruídos - em acordo com a NR-7 da Portaria 3214/78 (Ministério do Trabalho, 1978) -, sem que os trabalhadores tenham que se deslocar do local de trabalho, poupando, assim, tempo de produção.

Por sua vez, a ginástica laboral, outra prática encontrada na Sigma, tem sido vendida por empresas de consultoria e prestação de serviços como alternativa para mitigar o sobreesforço e o cansaço em funções repetitivas e penosas, transmitindo aos trabalhadores a sensação de que estão sendo "cuidados" pela empresa, embora não haja evidências científicas de que aquela prática contribua efetivamente para a prevenção das Lesões por Esforços Repetitivos (LER), se, por exemplo, as condições e a organização do trabalho não forem alteradas. Ao desenvolverem uma percepção positiva sobre o programa, há o risco de os trabalhadores serem induzidos a crer que se trata de uma medida que previne determinados agravos. Assim sendo, continuarão expostos às exigências de produtividade, sem que questionem seu real impacto sobre o corpo e a saúde.

Ainda na esfera da saúde, cabe observar que, de acordo com seus contingentes de trabalhadores e graus de risco, as empresas são obrigadas a manter um serviço especializado de segurança e medicina do trabalho, com atribuições eminentemente preventivas, conforme a NR-4 da Portaria 3214/78 (Ministério do Trabalho, 1978; Scopinho, 2003). Essa medida, embora implementada para proteger o trabalhador, nem sempre o protege, de fato. Na Sigma, tem sido comum o médico do trabalho, diante de uma queixa do trabalhador, medicá-lo durante a jornada para que ele possa seguir trabalhando tão logo se constate a redução dos sintomas que apresentava. Também tem sido prática recorrente não aceitar a licença médica integral solicitada por um trabalhador quando o atestado médico é emitido por um profissional das redes pública ou privada. Nesse caso, o médico da empresa põe em dúvida tanto a atitude do colega de profissão como, também, a queixa do trabalhador, criando o que Borsoi (2005) denominou "guerrilha dos médicos", na qual quem perde é sempre o trabalhador. No caso da Sigma, por ser uma empresa de grande porte, espera-se que existam tanto um serviço de medicina do trabalho como, por conseqüência, os conflitos entre o médico da empresa e os de fora em torno do reconhecimento da queixa do trabalhador. 
Não fazem parte dos benefícios oferecidos aos trabalhadores o transporte extensivo a todos, o pagamento de plano de assistência médica (comum em empresas de grande porte), a cesta básica, os prêmios por produtividade ou, mesmo, alguma iniciativa que implique melhoria efetiva das condições de trabalho. Isso tem explicação. No caso do transporte, significativo contingente de trabalhadores faz o trajeto casa-trabalho-casa a pé ou de bicicleta, às vezes num esforço físico extra que desonera seus empregadores e os expõe ao risco de acidentes de trajeto - por sinal, comuns entre trabalhadores da empresa, tendo em vista a inadequação da maior parte das vias urbanas do município a esses meios de transporte. A economia nos gastos com transporte, para a empresa, é possivelmente uma motivação importante para que ela priorize a contratação de moradores da localidade ou dos distritos mais próximos. Entretanto, a Sigma já vem recorrendo à força de trabalho residente nos distritos mais distantes, pois tem crescido entre os jovens da cidade uma valoração negativa do emprego nessa empresa, referida por eles como "a senzala de... [nome do município]" (Rigotto, 2004).

Quanto a alguma premiação financeira por produtividade ou à concessão de cestas básicas, são práticas simplesmente inexistentes. Segundo a gerência, trata-se de benefícios sobre os quais não há certeza de que possam ser mantidos por tempo indeterminado. Teme-se que a retirada de benefícios como esses, após serem concedidos, possa gerar conflitos entre os trabalhadores e a empresa, o que, é óbvio, esta esforça-se para evitar.

No que diz respeito à assistência, não há planos ou convênios que contemplem atendimentos médico, dentário e laboratorial. Nesses casos, é o sindicato que assume a concessão de algum auxílio, como convênios com clínicas, laboratórios etc., utilizando-se desse expediente para forçar a sindicalização dos trabalhadores, que, normalmente, vêem nisso a única razão ou vantagem para se sindicalizar ou permanecer sindicalizados. Ao fim e ao cabo, a empresa se libera de qualquer custo suplementar que possa ter impacto direto sobre a reprodução ou manutenção da força de trabalho, ficando os trabalhadores com o ônus do constante desgaste de seu vigor físico e de sua saúde.

O outro conjunto de ações da Sigma tem como alvo tanto os próprios trabalhadores como, também, a população local. São práticas realizadas de forma que possam integrar sua política de marketing: "Projeto Arte Sigma" para filhos de funcionários, "Sigma doa kits escolares a filhos de funcionários", "Sigma vai à escola", "Sigma na caminhada ecológica", "Sigma doa cestas básicas à população carente", colaboração com instituições filantrópicas, distribuição de "sopão mensal" para famílias de "classes menos favorecidas" etc. São iniciativas que visam a atingir tanto trabalhadores, quanto a população local, cumprindo, na realidade, alguns requisitos já previstos nos programas de responsabilidade social.

A Sigma insere, ainda, em sua lista de benefícios à coletividade, o tratamento da água e do esgoto da fábrica para reaproveitamento de água consumida pela própria empresa, embora essa seja uma exigência legal e, também, uma forma de racionalizar o uso (e o custo) dos recursos hídricos.

Ao lançar mão de práticas como essas, o que a empresa faz, concretamente, é muito mais chamar a atenção para si mesma, tornar-se referência no que tange à sua capacidade de absorver mão-de-obra e criar condições para cooptar não só os trabalhadores que contrata, mas também os demais moradores do lugar, que, quase sempre, têm um parente em seu quadro funcional. Nesse último caso, não se pode deixar de mencionar a política de contratação de novos trabalhadores por meio da indicação daqueles que já se encontram empregados. Estes, por sinal, vêem aí uma oportunidade de empregar pessoas de suas próprias famílias. Com isso, a empresa consegue fazer com que todos se esforcem para zelar por seus lugares na produção, pois um deslize de quem entrou por indicação de alguém já contratado pode comprometer o emprego de ambos e, obviamente, desacreditar aquele que indicou. 
Desse modo, a Sigma atua em duas frentes: de um lado, compromete os trabalhadores dentro da empresa; de outro, compromete suas famílias e o restante da população. Agindo assim, ela tende a construir em todos uma espécie de sentimento de devedores. Podem-se até questionar os salários, as condições de trabalho, as jornadas extensas, mas há sempre a possibilidade de defesa de uma empresa que, aparentemente, preocupa e solidariza-se com as pessoas do lugar. Dissemos "aparentemente" porque as medidas adotadas pela empresa em relação à população não se revertem em melhorias objetivas das condições de vida; sequer prevêem planos de preservação dos recursos naturais locais. $\mathrm{O}$ que parece haver, de fato, é uma preocupação, por parte da empresa, em preservar, em termos mínimos, a fonte de força de trabalho que ela precisa renovar com alguma regularidade.

Quanto à decisão de não oferecer benefícios que possam resultar em algum ganho que tenha impacto nos rendimentos do trabalhador, seja direta ou indiretamente, isso parece estar associado a dois aspectos. $\mathrm{O}$ primeiro diz respeito à percepção de que uma prática como essa pode se tornar um direito, o que implicaria, portanto, em uma questão jurídica que poderia ser levada adiante por um sindicato que se comprometesse com tal causa. $\mathrm{O}$ segundo tem a ver com um aspecto prático - no caso, a incorporação efetiva desses ganhos no orçamento doméstico regular do trabalhador, os quais, se fossem retirados, poderiam gerar um profundo descontentamento. Portanto, o que a Sigma oferece é apenas aquilo que, se for suprimido, além de não ser questionado como direito passível de perda, também não fará diferença significativa na vida do trabalhador.

Frente a isso, a opção da empresa recai sobre programas que não interferem na situação salarial ou orçamentária do trabalhador ou, mesmo, que possam causar impacto em suas condições de trabalho. Neste último caso, determinadas iniciativas sequer poderiam ser consideradas benefícios, uma vez que condições laborais adequadas são, antes de tudo, um direito do trabalhador e uma obrigação das empresas. Entretanto, é sabido que nem sempre interessa a elas investimentos nessa área - primeiro, por considerarem significativos os custos correspondentes e, segundo, por terem disponível um grande contingente de candidatos a um emprego.

Assim, as ações da Sigma não dão margem à construção de uma noção de garantia, de direito, mas apenas da percepção de doação ou de dádiva da empresa. A julgar pelo que afirma Borsoi $(2005,2007)$, essa percepção, pelos trabalhadores, de supostas dádivas por parte da empresa, pode estar associada a uma vivência prévia na qual predominavam condições de vida mais precárias e maior carência de oportunidades de trabalho com garantias mínimas. Então, uma experiência de vida e de trabalho menos penosa tende a ser vista com maior positividade, sendo ela atribuída à empresa, a qual, de alguma maneira, é percebida como o elemento que possibilita essa nova vivência.

No caso da Sigma, mesmo que se considerem as condições inadequadas de trabalho, os baixos salários e os benefícios pouco significativos que oferece, ela ainda surge como uma das melhores e únicas oportunidades para que os trabalhadores consigam manter uma condição de vida mais segura e algum acesso a bens de consumo naquele município. Como resultado, os trabalhadores vêem-se convencidos ou mesmo forçados a manterem-se gravitando em torno da fábrica, até durante o tempo supostamente livre.

Algumas das práticas da empresa visam, na realidade, construir uma espécie de sentimento de família e, portanto, de obrigatoriedade de vínculos que vão além da formalidade do contrato. É o que se pode depreender, por exemplo, da denominação de um coral composto por um grupo de trabalhadores: "Vozes da Família Sigma". Como uma família, todos devem participar da meta estabelecida pela empresa, que é produzir o máximo para que ela consiga permanecer competitiva no mercado, garantindo, assim, o emprego de todos. Esse sentimento de pertinência que a empresa tenta incutir entre os trabalhadores parece aproximar-se do que Sennett (2006) entende como lealdade, ou seja, um 
relacionamento participativo o suficiente para que as pessoas tendam a se sacrificar pela instituição, como se pode verificar em organizações militares, por exemplo. Ao final, o que a empresa parece tentar construir é um vínculo com base na dívida-dádiva, a partir da lógica do "é dando que se recebe".

\section{Considerações finais}

Gramsci (1978), ao referir-se ao modelo fordista de produção, dizia que sua efetividade, entre outras coisas, estava em sua capacidade de unir coerção e persuasão. Isso porque, de fato, a coerção não convence, pois, geralmente, os indivíduos podem tornar-se arredios quando não vêem sentido naquilo que lhes é imposto. Diante disso, é preciso persuadir, ou seja, tornar intrínseco o sentido extrínseco, fazendo-o percebido como construção do próprio sujeito. Para Borsoi (2005), a disciplina imposta precisa tornar-se autodisciplina; o controle externo deve ser sentido como autocontrole; cada gesto deve ter justificativa plausível e ser percebido como oriundo da própria conduta e do próprio pensamento.

Parece ser essa a base da gestão da fábrica Sigma e a chamada política de benefícios cumpre importante papel na consecução daqueles objetivos. Embora seja parte da profunda reestruturação do mundo laboral, o que ela adota é a conjugação de velhas e novas práticas no campo da organização e das relações de trabalho. De um lado, estão os trabalhadores que perseguem a velocidade da esteira e, de outro, os grupos ou células que correm contra o tempo para compensar trabalho demais para trabalhadores de menos. Em comum, todos têm o cronômetro como seu mais implacável controlador.

Por um lado, a empresa oferece condições precárias de trabalho, exige produtividade, cobra horas suplementares e ameaça de demissão aqueles que resistem a se submeter - e que o fazem por saber que não tirarão proveito disso. Por outro, oferece um conjunto de práticas que em nada impacta sobre o rendimento de "seus" trabalhadores nem suas condições objetivas de trabalho e de vida, mas que, apesar disso, são denominadas de "benefícios".

Com isso, a empresa lança mão de recursos que mais funcionam como meio de cooptação do que como benefícios propriamente ditos. Ao fazer com que os trabalhadores sintam-se "participantes" de seu grande empreendimento social e ao envolvê-los de maneira que se considerem colaboradores, colegas de seus empregadores, ela tenta, sim, construir em todos - trabalhadores e moradores da localidade - o sentimento de que são devedores de uma empresa doadora. Assim, poderá continuar a usufruir dos recursos naturais e sociais do lugar e a manter o controle sobre sua fonte de força de trabalho, sem que se sinta obrigada a retribuir tais usos e controles com melhorias objetivas nas condições de vida da população. Além disso, suas iniciativas fazem crer que todos são dependentes daquilo que ela, de fato, oferece: tão-somente um emprego por um magro salário.

\section{Referências}

Antunes, R. (1995). Adeus ao trabalho? Ensaio sobre as metamorfoses e a centralidade do mundo do trabalho. São Paulo: Cortez.

Antunes, R. (2000). Os sentidos do trabalho: ensaio sobre a afirmação e a negação do trabalho. São Paulo: Boitempo. 
Borsoi, I. C. F. (2005). O modo de vida dos novos operários: quando purgatório se torna paraíso. Fortaleza: Edições UFC.

Borsoi, I. C. F. (2007). O trabalho, o consumo e os novos operários: a experiência de trabalhadores em região de recente industrialização. In I. C. F. Borsoi \& R. A. Scopinho (Orgs.), Velhos trabalhos, novos dias: modos atuais de antigas atividades laborais (pp. 103-122). Fortaleza: Edições UFC. São Carlos: EDUFSCar.

Chiavenato, I. (1983). Introdução à teoria geral de administração. São Paulo: McGraw Hill.

Costa, A. C. \& Ferrari, I. (Orgs.). (1990). Consolidação das Leis do Trabalho (15ª ed.). São Paulo: LTR e EDUSP.

Gramsci, A. (1978). Americanismo e fordismo. In Obras Escolhidas (pp. 311-339). São Paulo: Martins Fontes.

Haesbaert, R. (1997). Des-territorialização e identidade: a rede "gaúcha" no Nordeste. Niterói: EDUFF.

Harvey, D. (2002). Condição pós-moderna. São Paulo: Loyola.

Hirata, H. (2002). Nova divisão sexual do trabalho? um olhar voltado para a empresa e a sociedade. São Paulo: Boitempo.

Humphrey, J. (1995). O impacto das técnicas "japonesas" de administração sobre o trabalho industrial no Brasil. In N. A. de Castro (Org.), A máquina e o equilibrista: inovações na indústria automobilistica brasileira (pp.113-143). São Paulo: Paz e Terra.

Krein, J. D. (2001). As mudanças institucionais e as relações de trabalho no Brasil após o Plano Real. Relatório de pesquisa. Campinas: Unicamp.

Ministério do Trabalho (1978). Portaria 3214 de 8 de junho de 1978. Aprova as Normas Regulamentadoras do Capítulo $\mathrm{V}$ do Título II da Consolidação das Leis do Trabalho, relativas à Segurança e Medicina do Trabalho. Brasília.

Noronha, E. G. \& Turchi, L. M. (2002). Cooperação e conflito: estudo de caso do complexo coureirocalçadista no Brasil (texto para discussão no 861). Brasília: IPEA.

Rigotto, R. M. (2004). O "progresso chegou". E agora? Tramas da (in)sustentabilidade e a sustentação simbólica do desenvolvimento. Tese de Doutorado, Programa de Pós-Graduação em Sociologia, Universidade Federal do Ceará, Fortaleza.

Rigotto, R. M. (2007). Maranguape, Ceará: sapateiros e bordadeiras, agora entre células e esteiras. In I. C. F. Borsoi \& R. A. Scopinho (Orgs.), Velhos trabalhos, novos dias: modos atuais de antigas atividades laborais (pp. 77-101). Fortaleza: Edições UFC. São Carlos: EDUFSCar.

Saes, D. A. M. de (2006). Direitos sociais e transição para o capitalismo. Estudos de Sociologia, 11 (20), 23-51.

Scopinho, R. A. (2003). Vigiando a vigilância: saúde e segurança no trabalho em tempos de qualidade total. São Paulo: Annablume e Fapesp.

Sennett, R. (2006). A cultura do novo capitalismo. Rio de Janeiro: Record.

Ximenes, V. M. (2004). Responsabilidade social e ambiental nas empresas: contribuições da psicologia social desde as áreas comunitária, ambiental e organizacional. In M. de F. S. Silva \& C. A. B. Aquino (Orgs.), Psicologia social: desdobramentos e aplicações (pp. 169-189). São Paulo: Escrituras.

\section{Endereço para correspondência:}

cristinaborsoi@uol.com.br, raquelrigotto@gmail.com 